\title{
Migration studies and toxicity evaluation of cyclic polyesters oligomers from food packaging adhesives
}

Ubeda, Sara; Aznar, Margarita; Rosenmai, Anna Kjerstine; Vinggaard, Anne Marie; Nerín, Cristina

Published in:

Food Chemistry

Link to article, DOI:

10.1016/j.foodchem.2019.125918

Publication date:

2020

Document Version

Peer reviewed version

Link back to DTU Orbit

Citation (APA):

Ubeda, S., Aznar, M., Rosenmai, A. K., Vinggaard, A. M., \& Nerín, C. (2020). Migration studies and toxicity evaluation of cyclic polyesters oligomers from food packaging adhesives. Food Chemistry, 311, [125918]. https://doi.org/10.1016/j.foodchem.2019.125918

\section{General rights}

Copyright and moral rights for the publications made accessible in the public portal are retained by the authors and/or other copyright owners and it is a condition of accessing publications that users recognise and abide by the legal requirements associated with these rights.

- Users may download and print one copy of any publication from the public portal for the purpose of private study or research.

- You may not further distribute the material or use it for any profit-making activity or commercial gain

- You may freely distribute the URL identifying the publication in the public portal 


\section{Journal Pre-proofs}

Migration studies and toxicity evaluation of cyclic polyesters oligomers from food packaging adhesives

Sara Ubeda, Margarita Aznar, Anna Kjerstine Rosenmai, Anne Marie Vinggaard, Cristina Nerín

PII: $\quad$ S0308-8146(19)32056-4

DOI: $\quad$ https://doi.org/10.1016/j.foodchem.2019.125918

Reference: $\quad$ FOCH 125918

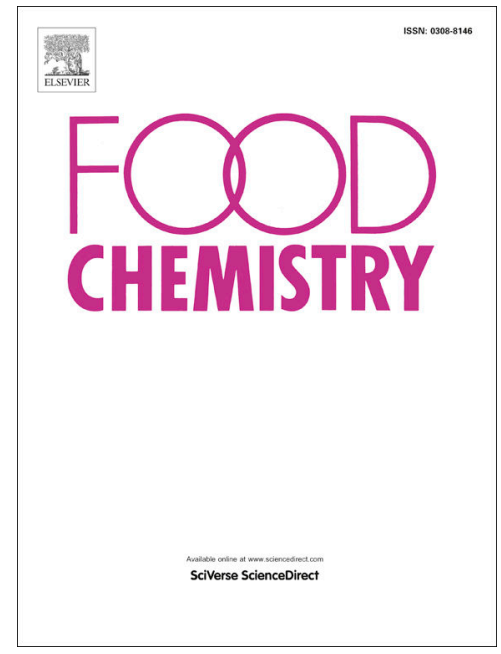

To appear in: $\quad$ Food Chemistry

Received Date: $\quad 15$ July 2019

Revised Date: $\quad 8$ October 2019

Accepted Date: $\quad 15$ November 2019

Please cite this article as: Ubeda, S., Aznar, M., Rosenmai, A.K., Vinggaard, A.M., Nerín, C., Migration studies and toxicity evaluation of cyclic polyesters oligomers from food packaging adhesives, Food Chemistry (2019), doi: https://doi.org/10.1016/j.foodchem.2019.125918

This is a PDF file of an article that has undergone enhancements after acceptance, such as the addition of a cover page and metadata, and formatting for readability, but it is not yet the definitive version of record. This version will undergo additional copyediting, typesetting and review before it is published in its final form, but we are providing this version to give early visibility of the article. Please note that, during the production process, errors may be discovered which could affect the content, and all legal disclaimers that apply to the journal pertain.

(C) 2019 Elsevier Ltd. All rights reserved. 


\section{1}

\section{Abstract}

\section{Migration studies and toxicity evaluation of cyclic polyesters oligomers from food packaging adhesives}

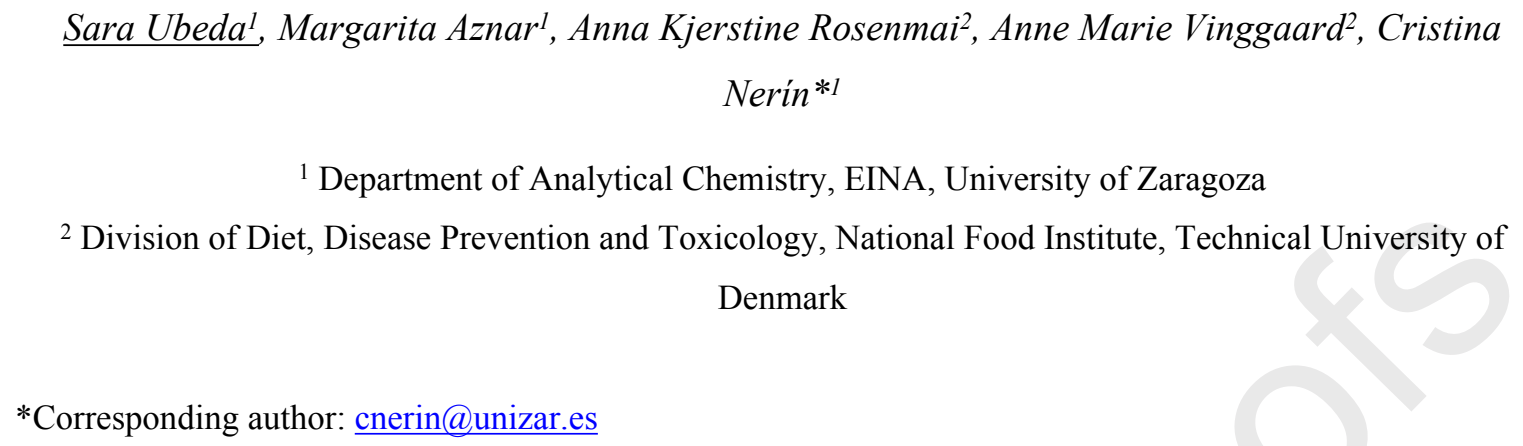

Multilayer materials used in food packaging are commonly manufactured with a polyurethane adhesive layer in its structure that may contain cyclic esters oligomers as potential migrants. However, little is known about their toxicity. In this work, two cyclic esters of polyurethane are evaluated in migration from 20 multilayer packaging samples. They were composed by adipic acid (AA), diethylene glycol (DEG) and isophthalic acid (IPA) and their structure was AA-DEG and AA-DEG-IPA-DEG. The concentration of these compounds in migration exceeded the maximum level established by Regulation EU/10/2011 (10 $\left.\mathrm{ng} \mathrm{g}^{-1} \mathrm{ng} / \mathrm{g}\right)$. Bioaccessibility of both compounds was evaluated by studying gastric and intestinal digestion. The studies showed that the concentration of the compounds decreased during digestion and that their hydrolysed molecules increased. Furthermore, endocrine activity in vitro assays were performed. A weak androgen receptor antagonism was identified, whereas no arylhydrocarbon receptor activity or binding to the thyroid hormone transport protein was found.

Keywords: oligomers, migration, NIAS, polyurethane adhesive, food packaging, bioaccesibility, endocrine activity 


\section{Introduction}

Food contact materials (FCMs) protect food from external contamination and preserve the nutritional value as well as the physical and sensory quality of food. However, it is important to control the migration of compounds from packaging materials to foods, as it may lead to the transference of unwanted substances that can make food less safe for consumption or that may alter its sensory and nutritional characteristics. It is necessary, therefore, to identify the compounds that are present in the different packaging materials and that can be potential migrants (Wrona \& Nerín, 2019). Substances in FCM can be intentionally or non-intentionally added (IAS and NIAS). NIAS are difficult to control, as they are often not chemically well characterized and are present at low concentration levels. This complicates its identification and therefore, advanced techniques with high sensitivity and resolution are needed (Margarita Aznar, Ubeda, Dreolin, \& Nerín, 2019; Hoppe, de Voogt, \& Franz, 2016; Nerin, Alfaro, Aznar, \& Domeño, 2013; Pietropaolo, Albenga, Gosetti, Toson, Koster, Marin-Kuan, et al., 2018).

In the case of multilayer packaging materials, where the material is made of multiple polymer layers bonded by adhesives, migration can occur not only from the material that is in direct contact with food, but also from internal layers of the material including the adhesives. This process is due to diffusion and partition processes of the compounds between the different layers (Margarita Aznar, Vera, Canellas, Nerín, Mercea, \& Störmer, 2011; Tehrany \& Desobry, 2004). Due to its thermal stable-1ow temperature properties, flexibility, durability and impact resistance, polyurethane (PU) is the most commonly used adhesive for flexible multilayer structures (Heath \& Cooper, 2013). PU adhesives are also used in other applications such as in the assembly of shoes, automotive interiors, windshield bonding or textile laminates (Engels, Pirkl, Albers, Albach, Krause, Hoffmann, et al., 2013). Therefore, there can be different potential exposure sources of these compounds.

PU adhesive synthesis is a reaction between di-isocyanates and linear polyester compounds, where the latter are produced by polycondensation reaction between polyols (ethylene glycol, EG; diethylene glycol, DEG; 1,4-butanediol, BD; neopentyl glycol, NPG; 1,6-hexanediol, HD) and aliphatic or aromatic carboxylic acids (adipic acid, AA; isophthalic acid, IPA). When the last reaction does not proceed under equilibrium conditions, it favors the formation of short chain cyclic polyesters, so-called lactones, in addition to linear polyesters (Shrikhande, 2012). These cyclic esters can also be considered oligomers as they are formed by several monomer units. The formation of cyclic esters is undesirable from an industrial point of view as they can impair the physical properties of the material (Eceiza, Martin, de la Caba, Kortaberria, Gabilondo, Corcuera, et al., 2008; Shrikhande, 2012; Zhang, 2014). Furthermore, from a food packaging perspective, these 
64

65

66

67

68

69

70

71

72

73

74

75

76

77

78

79

80

81

82

83

84

85

86

87

88

89

90

91

92

93

94

95

unwanted by-products are considered NIAS and, as demonstrated previously (Félix, Isella, Bosetti, \& Nerín, 2012; Gómez Ramos, Lozano, \& Fernández-Alba, 2019; Nerin, Alfaro, Aznar, \& Domeño, 2013; Ubeda, Aznar, \& Nerín, 2018; Úbeda, Aznar, Vera, Nerín, Henríquez, Taborda, et al., 2017; Zhang, Kenion, Bankmann, Mezouari, \& Hartman, 2018) have a high migration potential. Migration of theses oligomers could be seen as microplastics coming from plastic FCMs (Ubeda, Aznar, Alfaro, \& Nerín, 2019). As they are NIAS, they are not included in any database and often commercial standards are not available, making identification and confirmation a difficult process. Other byproducts coming from PU are the primary aromatic amines (PAAs) which are possibly carcinogenic to humans (Campanella, Ghaani, Quetti, \& Farris, 2015).

There is no specific European legislation for food packaging adhesives and its components, though some countries such as Switzerland have a national legislation (Swiss-Confederation, 2013). However, when PU adhesive are used in the manufacture of multilayer plastic for FCM they are controlled by Regulations 1935/2004/EC (EC, 2004) and 10/2011/EU (EC, 2011). The Regulation states that FCM components must not be transferred into food in quantities that may harm human health. The oligomers are not specified in the Regulation 10/2011/EU (EC, 2011), thus a limit of migration to food simulants of $10 \mathrm{ng} \mathrm{g}^{-1} \mathrm{ng} / \mathrm{g}$ should not be exceeded.

There is little information on the hazards of oligomers. This is partially due to the lack of commercial standards necessary for toxicological testing. It has often been assumed that oligomers have the same toxicity as their starting monomers and that they should therefore be covered by their toxicological evaluation (Grob, Camus, Gontard, Hoellinger, Joly, Macherey, et al., 2010; Nelson, Patton, Arvidson, Lee, \& Twaroski, 2011). However, it is evident that reaction products can have different properties. According to EFSA (EFSA, 2008), when the polymer is formed by the polymerization of an approved monomer, its lack of genotoxicity is established by the data on the monomer, and no requirement for experimental data on the polymer itself are needed such as for cyclic butylene terephthalate (EFSA, 2009). In some cases, the same toxicity results of monomers and their oligomers have been demonstrated, such as for oligomers of halocarbon 3.1 oil and chlorotrifluoroethylene trimer acid (Nelson, Patton, Arvidson, Lee, \& Twaroski, 2011). In contrast, it has been demonstrated in other cases that the toxicological profile of the reaction products and starting substances differed, such as the oligomers of styrene (Gelbke, Banton, Block, Dawkins, Leibold, Pemberton, et al., 2018). Thus, it is important to test the toxic potential, not only of the starting material, but also of the present oligomers. Initially, these tests can be done by in vitro examinations. 
96

97

98

99

100

101

102

103

104

105

106

107

108

109

110

111

112

113

114

115

116

117

118

119

120

121

122

123

124

125

126

127

The safety evaluation from the Office of Food Additive Safety (OFAS) states that oligomeric materials with a molecular weight below $1000 \mathrm{Da}$ are important from a toxicological point of view as they could migrate into food and be absorbed in the gut (Nelson, Patton, Arvidson, Lee, \& Twaroski, 2011). Hence, it is crucial to assess the safety of those oligomers with lower molecular weights. However, as far as the authors know, the toxicological properties are not well characterized.

In addition, foodstuff undergoes a series of processes before being absorbed into the body, such as gastric and intestinal digestions. These processes might change the concentrations of substances available to be absorbed and could even lead to the formation of new compounds. These changes may have implications for the final toxicity. Thus, it is important to study the bioaccessibility as well as the gastrointestinal degradation of the migrant compound to enhance the understanding of the chemical composition of the fraction available for absorption (M. Aznar, Gómez-Estaca, Vélez, Devesa, \& Nerín, 2013).

Exogenous compounds such as endocrine disrupting chemicals (EDCs) are of special interest because they mimic, block or in other ways alter the activities of endogenous hormones. In vitro assays have been developed for a wide range of toxicological effects including induction of cytochrome P450 enzymes, androgenic activity and thyroid disruption. The binding or blocking of steroid hormone receptors like the androgen (AR) receptor by chemicals has been a significant focus for assessment of endocrine disruption potential as this receptor has got a pivotal role in development of male reproductive health (Schwartz, Christiansen, Vinggaard, Axelstad, Hass, \& Svingen, 2019). Increasing attention is now being given to the ability of chemicals to disrupt the thyroid hormones system, which play an important role in ensuring normal development of the embryonic brain (Duntas \& Stathatos, 2015). Another important assay is the aryl hydrocarbon receptor (AhR) assay that - when activated - leads to increased metabolism of chemicals, drugs, and hormones and which also plays an important role in our immune defense (Esser \& Rannug, 2015).

In this study, the objective was to investigate migration of two cyclic esters from multilayer packaging material based on PU adhesives, as well as to evaluate their bioaccessibility to the body. The potential formation of new compounds during gastrointestinal digestion was also evaluated. Furthermore, the in vitro endocrine disruptive potential of both compounds was studied in assays covering androgen receptor and aryl hydrocarbon receptor activity, as well as binding to transthyretin - an important transport protein of thyroid hormones. 


\section{Materials and methods}

\subsection{Test chemical}

Two cyclic ester oligomers, AA-DEG and AA-DEG-IPA-DEG, composed of diethylene glycol (DEG), adipic acid (AA) and isophthalic acid (IPA) were tested. Test substances were chemically synthesizedsupplied by a nondisclosed adhesives company. and tTheir structures and purity were confirmed by NMR at the University of Zaragoza. The high resolution mass spectra of these compounds will be described in the Results section.

\subsection{Samples}

Twenty multilayer plastic materials mainly intended for FCM and the storage of biological fluids were tested (samples code: 1S-20S). Polyurethane was used as adhesive in the manufacture of all evaluated samples. The materials contained a combination of aluminium (Al), polyethylene terephthalate (PET), polyamide (PA), polypropylene (PP) and polyethylene (PE) and had different thickness. They were supplied by different manufacturing companies and are described in Table 1 .

\subsection{Migration test}

For the migration experiments, multilayer materials were cut $\left(10 \times 10 \mathrm{~cm}^{2}\right)$, folded in half and thermo-sealed. The internal surface of the bags was $0.64 \mathrm{dm}^{2}$. Afterwards, they were filled with different simulants. The simulants used, as well as the temperatures and times of the migration experiments were selected depending on the intended use of the material and according to EU/10/2011 (EC, 2011). Ultrapure water (Milli-Q Ultramatric Wasserlab GR 216071, Madrid, Spain) and ethanol $10 \%$ were used as aqueous simulants and ethanol $95 \%$ (Panreac, Barcelona, Spain) as fat simulant. Water was used when the materials were intended for biological fluids. When samples were intended for food contact, $10 \%$ ethanol was selected for food with hydrophilic character and $95 \%$ ethanol for fat and dry food.

EU/10/2011 (EC, 2011) established that for contact times above 30 days at room temperature, materials should be tested in an accelerated test at $60{ }^{\circ} \mathrm{C}$ for a maximum of 10 days. For contact times longer than 2 days at room temperature, three days at $40^{\circ} \mathrm{C}$ was selected. For pasteurized materials, the conditions were different. In this case, bags were introduced in a stainless steel extraction cells, completing the cell space with water and maintaining the assembly for $30 \mathrm{~min}$ at $121{ }^{\circ} \mathrm{C}$. This way, the ethanol is kept in liquid phase during the assay, due to the pressure exerted under these conditions by the water inside the cell. In the case of biological samples, tests were performed at $40^{\circ} \mathrm{C}$ for 3 days on the basis of its use. 
159

160

161

162

163

164

165

166

167

168

169

170

171

172

173

174

175

176

177

178

179

180

181

182

183

184

185

186

187

188

Although the materials had dissimilar end use, the migration concentrations were corrected to $6 \mathrm{dm}^{2}$ of packaging material per $1 \mathrm{~kg}$ simulant, in accordance with European Regulation 10/2011 (EC, 2011) to compare results. Three replicates of every test were analysed. Samples were analysed by UPLC-QTOF.

\subsection{Digestion assays}

The protocol was prepared according to 2008 EFSA guide (EFSA, 2008). The experiments were carried out in three independent replicates and analysed by UPLC-QqQ (MRM mode) and UPLCQTOF.

\subsubsection{Gastric digestion}

Gastric simulant was $0.07 \mathrm{M} \mathrm{HCl}$ (35\%, Panreac). The $\mathrm{pH}$ of the solution was $1.2 \pm 0.1$.

An aliquot of $100 \mu \mathrm{L}$ of cyclic ester $(100 \mu \mathrm{g} / \mathrm{g}$ water) was added to $10 \mathrm{~mL}$ of gastric simulant (final concentration $1 \mu \mathrm{g} / \mathrm{g}$ ) and afterwards heated at $37^{\circ} \mathrm{C}$. This solution was maintained with agitation at $37^{\circ} \mathrm{C}$ for $4 \mathrm{~h}$. During digestion, aliquots of $1 \mathrm{~mL}$ were taken at 4 different times $\left(\mathrm{t}_{0}, \mathrm{t}_{1 \mathrm{~h}}, \mathrm{t}_{2 \mathrm{~h}}\right.$ and $\left.\mathrm{t}_{4 \mathrm{~h}}\right)$ and neutralized with $250 \mu \mathrm{L} 0.02 \mathrm{M}$ sodium hydroxide $(\mathrm{NaOH})(1 \mathrm{M}$, Panreac) at $\mathrm{pH} 6$.

\subsubsection{Intestinal digestion}

Intestinal simulant was carried out with pancreatin from porcine pancreas (Sigma Aldrich) according to 2008 EFSA Guide (EFSA, 2008).

For its preparation, $6.8 \mathrm{~g}$ of potassium dihydrogen orthophosphate $\left(\mathrm{KH}_{2} \mathrm{PO}_{4}\right)$ (Pro Analyse Merck) was dissolved in $250 \mathrm{~mL}$ water and transferred to a $1 \mathrm{~L}$ volumetric flask to which $190 \mathrm{~mL} 0.2 \mathrm{M}$ $\mathrm{NaOH}$ and $400 \mathrm{~mL}$ water were added and mixed briefly. Then, an amount of $10 \mathrm{~g}$ of pancreatin extract was introduced into a $250 \mathrm{~mL}$ beaker with little water to make a homogenous paste. After this, the paste was gradually diluted with small portions of water, stirring well after each dilution to give approximately $150 \mathrm{~mL}$ of a lump-free solution. The solution was transferred to the $1 \mathrm{~L}$ volumetric flask where $0.5 \mathrm{~g}$ of sodium taurocholate (Sigma-Aldrich) were added and shaken. Then, water was added leaving space to adjust $\mathrm{pH}$ to $7.5 \pm 0.1$ with $0.2 \mathrm{M} \mathrm{NaOH}$.

Digestion assay was carried out adding $50 \mu \mathrm{L}$ of $100 \mu \mathrm{g}_{-} \mathrm{g}^{-1}$ of cyclic ester in water to $10 \mathrm{~mL}$ of intestinal simulant previously tempered at $37^{\circ} \mathrm{C}$ and $\left(500 \mathrm{ng} \mathrm{\textrm {g } ^ { - 1 }} \mathrm{ng} / \mathrm{g}\right.$ final concentration). This dissolution was maintained at $37^{\circ} \mathrm{C}$ with constant agitation. During digestion, aliquots of $1 \mathrm{~mL}$ were taken and evaluated at 4 different time points $\left(t_{0}, t_{1 h}, t_{2 h}\right.$ and $\left.t_{4 h}\right)$. In order to precipitate the proteins present in the aliquot, $1 \mathrm{~mL}$ of $20 \%(\mathrm{w})$ trichloroacetic acid (TCA) (Sigma-Aldrich) was added to 
189

190

191

192

193

194

195

196

197

198

199

200

201

202

203

204

205

206

207

208

209

210

211

212

213

214

215

216

each aliquot and then cooled on ice bath for $30 \mathrm{~min}$. Successively, the solutions were centrifuged at $8000 \mathrm{rpm}$ for $15 \mathrm{~min}$ and $1 \mathrm{~mL}$ of the supernatant was filtered (PET $0.22 \mu \mathrm{m}$ ) and transferred to a vial with $250 \mu \mathrm{L}$ of $0.02 \mathrm{M} \mathrm{NaOH}$ to adjust to neutral $\mathrm{pH}$.

In order to check if the addition of TCA could degrade the cyclic esters, $500 \mu \mathrm{L}$ of cyclic ester were mixed with $500 \mu \mathrm{L}$ of TCA and $250 \mu \mathrm{L}$ of $0.02 \mathrm{M} \mathrm{NaOH}$ and the results were compared to the cyclic esters without TCA addition. The signals were similar in both experiments and therefore it was concluded that TCA did not hydrolyse the cyclic ester.

\subsection{Instrumentation and conditions}

\subsubsection{Ultra-performance liquid chromatography analysis (UPLC)}

Chromatography was performed using an Acquity ${ }^{\mathrm{TM}}$ system with a UPLC BEH C18 column of $2.1 \mathrm{~mm} \times 100 \mathrm{~mm}$ and $1.7 \mu \mathrm{m}$ particle size supplied by Waters (Milford, MA, USA). The column temperature was $40{ }^{\circ} \mathrm{C}$ and the column flow was $0.3 \mathrm{~mL} / \mathrm{min}$. The sample injection volume was $10 \mu \mathrm{L}(\mathrm{QTOF})$ and $5 \mu \mathrm{L}(\mathrm{QqQ})$. Mobile phases were water (phase A) and methanol (phase B) with $0.1 \%$ formic acid. Chromatography started at $98 / 10$ phase $\mathrm{A} /$ phase $\mathrm{B}$, changed to $0 / 100$ in 7 minutes.

\subsubsection{MS-QTOF conditions}

MS-QTOF analysis was performed in a Xevo G2 mass spectrometer supplied by Waters (Milford, MA, USA). The detector consisted of an API source (atmospheric pressure ionization) with an electrospray ionization (ESI). The electrospray probe was used in positive (ESI + ) and negative (ESI-), both in sensitivity mode. The accuracy and reproducibility of all the analyses were guaranteed by use of a LockSpray ${ }^{\mathrm{TM}}$. The mass range considered was from 50 to $1200 \mathrm{Da}$. The capillary voltage was $2.5 \mathrm{kV}$, the cone voltage was $30 \mathrm{~V}$ and the source temperature was $120{ }^{\circ} \mathrm{C}$. The desolvation gas temperature and flow were $450{ }^{\circ} \mathrm{C}$ and $550 \mathrm{~L} \mathrm{~h}^{-1}$ respectively. The cone gas flow was $20 \mathrm{~L} \mathrm{~h}^{-1}$

The acquisition was carried out in $\mathrm{MS}^{\mathrm{E}}$ mode with two functions; acquiring at low-energy (function 1) to obtain information about the precursor ion and at high energy (function 2) to provide information about fragment ions. The collision ramp energy was from 15 to $30 \mathrm{~V}$.

MassLynx v.4.1 software (Waters, Milford MA, USA) was used to analyse the samples. 


\subsubsection{MS-QqQ conditions}

MS-QqQ analysis was performed in TQ mass spectrometer from Waters (Milford, MA, USA). The UPLC system was coupled with an ESI probe to the QqQ. The electrospray probe was used in positive (ESI+) and acquisition was performed in MRM_(multiple reaction monitoring) mode. The parameters used were as follow: capillary voltage was $3.5 \mathrm{kV}$, source temperature was $150^{\circ} \mathrm{C}$, desolvation temperature $450^{\circ} \mathrm{C}$, cone gas flow $60 \mathrm{Lh}^{-1}$, and desolvation gas flow $600 \mathrm{Lh}^{-1}$.

The parent ion was $217.1[\mathrm{MH}+]$ for AA-DEG and the mass transitions $217.1 \rightarrow 173.1,217.1 \rightarrow$ 155.1 and $217.1 \rightarrow 111.05$ were monitored. The parent ion used for AA-DEG-IPA-DEG was $453.18[\mathrm{MH}+]$ and mass transitions $453.18 \rightarrow 237.08,453.18 \rightarrow 193.05$ and $453.18 \rightarrow 155.07$ were monitored. Cone and collision voltages were optimized from 20 to $70 \mathrm{~V}$. Finally, $30 \mathrm{~V}$ cone voltage and $20 \mathrm{~V}$ were selected as optimum values for both compounds.

Monomers were measured under the same conditions but in negative (ESI-) mode for AA and IPA and positive mode (ESI+) for DEG. In both cases the analysis was performed in SIR mode (single ion recording), being the ions monitored:145.05 [M-H]- $165.02[\mathrm{M}-\mathrm{H}]^{-}$and $129.3[\mathrm{MNa}]^{+}$for AA, $\underline{\text { IPA and DEG respectively. }}$

MassLynx v.4.1 and QuanLynx software were used to analyse the samples.

\subsection{In vitro endocrine activity}

Stock solutions of AA-DEG and AA-DEG-IPA-DEG of $100 \mathrm{mM}$ were prepared in dimethyl sulfoxide (DMSO) (Sigma-Aldrich, Copenhagen, Denmark).

\subsubsection{Androgen receptor (AR) reporter gene assay}

The potential of the test substances to affect AR activity was tested in an AR reporter gene assay using a stably transfected AR-EcoScreen ${ }^{\mathrm{TM}}$ cell line based on Chinese hamster ovary cell line (CHO). The protocol was essentially according to the OECD test guideline (Guidelines for the Testing of Chemicals, 2016). The cells contain three stably transfected constructs: a human androgen receptor expression construct, a firefly luciferase reporter construct with an androgen response element, and a renilla luciferase reporter construct. The latter is used to examine compromised cell viability.

Cells were cultured in Phenol Red Free Gibco ${ }^{\circledR}$ Dulbecco's Modified Eagle Medium F-12 Nutrient Mixture (D-MEM/F-12) supplemented with 5\% fetal bovine serum (FBS), $200 \mu \mathrm{g} / \mathrm{mL}$ zeonin, 100 
247

248

249

250

251

252

253

254

255

256

257

258

259

260

261

262

263

264

265

266

267

268

269

270

271

272

273

274

275

276

277

278 $\mu \mathrm{g} / \mathrm{mL}$ hygromycin, 100 units $/ \mathrm{mL}$ penicillin and $100 \mu \mathrm{g} / \mathrm{mL}$ streptomycin. All medium components were supplied by InvitrogenTM, Life TechnologiesTM (Carlsbad, California, USA).

Cells were seeded in white 96-well plates (Perkin Elmer) to a final concentration of $9 \times 10^{3}$ cells/well in assay medium (Phenol Red Free DMEM F-12 supplemented with $5 \%$ dextran treated FBS (DCC-FBS), 100 units $/ \mathrm{mL}$ penicillin and $100 \mu \mathrm{g} / \mathrm{mL}$ streptomycin). The cells were incubated overnight at $37{ }^{\circ} \mathrm{C}$ in a humidified atmosphere of $5 \% \mathrm{CO}_{2}$. Successively, medium was removed and new assay medium was added. Test substances and positive controls were added using HP D300 Digital Dispenser (Tecan Group Ltd., Zürich, Switzerland). R1881 (Perkin Elmer, Skovlunde, Denmark) and hydroxyflutamide (OHF) (Toronto Research Chemicals, Toronto, Canada) was included in all independent experiments to ascertain assay performance in agonist and antagonist mode, respectively, in concentrations ranging from 0.002-2.7 $\mathrm{nM}$ and 31-8000 $\mathrm{nM}$, respectively. In the antagonist mode of the assay, R1881 was added to all wells at a concentration of $0.1 \mathrm{nM}$. Test chemicals were tested in concentrations of $12.5,25,50,100$, and $200 \mu \mathrm{M}$. DMSO was used as vehicle control and was kept constant in all wells $(0.2 \%)$ - a non-cytotoxic concentration (data not shown). The cells were incubated with test chemicals for 20-24 h.

Dual-Glo Luciferase Assay System from Promega Corporation (Madison, Wisconsin, USA) was used to measure firefly and renilla luciferase activity. Luminescence was measured on a LUMIstar ${ }^{\circledR}$ Galaxy luminometer (BMG LABTECH, Offenburg, Germany). $100 \mu \mathrm{L}$ Dual-Glo ${ }^{\circledR}$ Luciferase Reagent was added to each well and the plates were placed on a horizontal shake for $10 \mathrm{~min}$. The firefly luminescence was then measured. Successively, $60 \mu \mathrm{L} /$ well of Dual-Glo ${ }^{\circledR}$ Stop \& Glo ${ }^{\circledR}$ was added. After 10 minutes shaking luminescence was measured. Seven independent experiments were conducted for each test chemical and each exposure concentration was tested in triplicates within the independent experiment.

\subsubsection{Aryl hydrocarbon receptor (AhR) reporter gene assay}

The potential of the test substances to affect AhR activity was tested in an AhR reporter gene assay. The stably transfected rat hepatoma (H4IIE-CALUX) cells obtained from Dr. Michael Denison (University of California, USA) were used and the assay was performed as described previously (Rosenmai, Taxvig, Wedebye, Dybdahl, Vinggaard, Pedersen, et al., 2014).

Cells were cultured in Minimum Essential Medium alpha (MEM $\alpha$ ) supplemented with 5\% fetal bovine serum (FBS), 100 units $/ \mathrm{mL}$ penicillin, $100 \mu \mathrm{g} / \mathrm{mL}$ streptomycin and $100 \mu \mathrm{g} / \mathrm{mL}$ fungizone. Medium components were supplied by InvitrogenTM, Life Technologies TM (Carlsbad, California, USA). 
279 Cells were seeded in white clear-bottomed 96-well plates (Corning ${ }^{\circledR}$ Inc., Corning, New York, 280 USA) at a concentration of $22 \times 10^{3}$ cells/well in assay medium (MEM $\alpha$ supplemented with $1 \%$ 281 FBS and 100 units $/ \mathrm{mL}$ penicillin, $100 \mu \mathrm{g} / \mathrm{mL}$ streptomycin and $100 \mu \mathrm{g} / \mathrm{mL}$ fungizone). For cell 282 viability studies, cells were seeded in black clear-bottomed 96-well plates (Corning ${ }^{\circledR}$ Inc., Corning, 283 New York, USA) at a concentration of $11 \times 10^{3}$ cells/well in assay medium. Cells were incubated 284 for $24 \mathrm{~h}$.

285 Successively, medium was exchanged and test substances and controls were added manually. Test 286 substances were tested in nine 2-fold dilutions ranging from 0.8-200 $\mu \mathrm{M}$. 2,3,7,8287 Tetrachlorodibenzo-p-dioxin (TCDD) (AACN Standards) was used as a positive control and tested 288 in concentrations ranging from 0.5-3000 pM. The vehicle was kept constant in all wells $(0.2 \%)-\mathrm{a}$ non-cytotoxic concentration (data not shown). The cells were incubated with test chemicals for 20$24 \mathrm{~h}$.

291 At experiment termination, cells were lysed with $25 \mu \mathrm{L} /$ well lysis buffer $(25 \mathrm{mM}$ of triphosphate 292 (Sigma Aldrich), $15 \%$ glycerol (VWR/BB), $1 \%$ triton X (Sigma Aldrich), 1 mM dithiothreitol 293 (Sigma Aldrich), and $8 \mathrm{mM} \mathrm{MgCl}_{2}$ (Sigma Aldrich)) and left on shaker table for approximately 20 $294 \mathrm{~min}$. Successively, $40 \mu \mathrm{L} /$ well luciferin solution were injected automatically and luminescence was 295 measured on LUMIstar ${ }^{\circledR}$ Galaxy luminometer.

296 Cell viability was examined by use of resazurin. At experiment termination medium was removed 297 and $100 \mu \mathrm{L}$ of a $5 \mu \mathrm{g} / \mathrm{mL}$ resazurin solution (Sigma Aldrich) was added to each well. Plates were 298 left to incubate for $3 \mathrm{~h}$ at $37^{\circ} \mathrm{C}, 5 \% \mathrm{CO}_{2}$, and a humidified atmosphere. Fluorescence was measured 299 on EnSpire (Perkin Elmer) with an excitation and emission wavelength of $560 \mathrm{~nm}$ and $590 \mathrm{~nm}$, 300 respectively.

301 Three independent experiments were conducted for each test chemical with each exposure 302 concentration in triplicates.

$303 \quad$ 2.6.3 ANSA-TTR displacement assay

304 Binding of test chemicals to transthyretin (TTR) was examined in the ANSA-TTR displacement 305 assay. The ANSA fluorophore (8-Anilino-1-naphthalene sulfonic acid ammonium salt) increases its 306 fluorescence signal when bound to TTR, whereas the signal is reduced when ANSA is displaced by 307 competition with thyroid hormones or exogenous substances.

308 Standard solutions in 1\% DMSO were mixed in a black flat bottom 96-well plate (PerkinElmer, 309 Skovlunde, Denmark) with $0.6 \mu \mathrm{M}$ ANSA (Sigma Aldrich) and $0.5 \mu \mathrm{M}$ TTR (Sigma Aldrich) in 
310

311

312

313

314

315

316

PBS. Test substance concentrations were 50, 100 and $200 \mu \mathrm{M}$. After $2 \mathrm{~h}$ of incubation at $4^{\circ} \mathrm{C}$, the plate was gently shaken for $10 \mathrm{~s}$ and fluorescence was measured (Enspire, Perkin Elmer). Negative controls only with $0.6 \mu \mathrm{M}$ ANSA, ANSA-TTR positive controls, and T4 (thyroxine) (Sigma Aldrich) $0.156,0.625$ and $2.5 \mu \mathrm{M}$ displacement controls were included on every plate. ANSA fluorescence was measured with excitation filter $380 \pm 20 \mathrm{~nm} / \mathrm{emission}$ filter $475 \pm 20 \mathrm{~nm}$ ). The experiment was repeated in three independent experiments with each exposure concentration tested in triplicates within each independent experiment.

\subsubsection{Data processing}

For AR and AhR reporter assay data, each data point within the independent experiment was normalized to the mean of the plate controls. Successively, means from independent experiments were pooled. In the ANSA-TTR displacement assay, the fluorescence from the negative control was subtracted, and data were expressed as fluorescence relative to the ANSA-TTR maximal fluorescence (positive control). Each data point was normalized against the mean of the plate control and means from the three experiments were pooled.

Kruskal-Wallis test (Dunn's post hoc test) was used to examine differences between exposed groups and controls and a p-value of $<0.05$ was perceived as statistically significant. All data processing and statistical analyses were performed in GraphPad Prism 5 (GraphPad Software Ic, La Jolla, CA, USA).

\section{Results and discussion}

\subsection{Migration assays by UPLC-QTOF}

Cyclic esters were quantified by external calibration with AA-DEG and AA-DEG-IPA-DEG standards. The analytical parameters of UPLC-QTOF are shown in Table 2, including linearity, limit of detection (LOD) and limit of quantification (LOQ).

Table 1 summarizes the migration values ( $\left.\mathrm{ng} \mathrm{g}^{-1}\right)$ of both cyclic esters in 20 different samples. The concentration of the cyclic esters in migration was highly variable but AA-DEG migration values were in all cases higher than the AA-DEG-IPA-DEG values. AA-DEG oligomer was in all migration samples between 20-994 $\mathrm{ng} \mathrm{g}^{-1}$ except for $17 \mathrm{~S}$ that was below of limit of migration according to legislation (10 $\left.\mathrm{ng} \mathrm{g}^{-1}\right)$. However, AA-DEG-IPA-DEG oligomer was only present in concentration values between 4 and $346 \mathrm{ng} \mathrm{g}^{-1}$ in 8 out of the 20 samples. To clarify, the detection 
339 and quantification limits of the method were calculated and reported in Table 2 taking into account

340 the dimension of the bags and the ratio $6 \mathrm{dm}^{2}$ per $1 \mathrm{~kg}$ simulant according to EU/10/2011.

341 For most multilayer materials, migration of the cyclic esters exceeded the migration limit established 342 by EU/10/2011 (EC, 2011) for not-listed substances, which is $10 \mathrm{ng} \mathrm{g}^{-1}$. Therefore, only the sample 343 17S should comply with the EU Regulation. Nevertheless, when a compound is not listed in the 344 regulation, the Threshold of Toxicological Concern (TTC) approach can be used (EFSA, 2012). This 345 approach assigns a theoretical toxicity class according to the compound chemical structure and 346 Cramer rules (G. M. Cramer, Ford, \& Hall, 1978). All the compounds are classified into three 347 classes according to its toxicity: class I (low toxicity), class II (intermediate class) and class III (high 348 toxicity), and a recommended value of maximum daily intake for each class is established (1.8, 0.54 349 and $0.09 \mathrm{mg} /$ person/day, respectively). Toxtree software was used to estimate the theoretical toxicity 350 of the cyclic esters. According to the TTC approach, both cyclic esters are classified as Cramer class 351 III (high toxicity) and hence the maximum daily intake should be below $0.09 \mathrm{mg} /$ person/day (G. M. 352 Cramer, Ford, \& Hall, 1978). The maximum recommended migration value according to the 353 maximum daily intake can be calculated with the Estimated Daily Intake (EDI) equation described 354 by FDA:

356 where $3 \mathrm{~kg}$ corresponds to the total food intake per person/day and $\mathrm{CF}$ is the consumption factor 357 (daily fraction of food that is expected to be in contact with the packaging material). For adhesives, 358 CF value is 0.14 . Therefore, the maximum recommended migration for these compounds according 359 to FDA would be $\mathbf{2 1 4} \mathbf{n g} \_\mathbf{g}-1$.

360 According to EFSA (PlasticsEurope, 2014), the Estimated Daily Intake (EDI) equation is different:

362 where $1 \mathrm{~kg}$ corresponds to the total food eat per person/day. This equation is more restricted than 363 the FDA equation. In this case, the maximum recommended migration for these compounds would be $90 \mathrm{ng} \mathrm{g}^{-1}$.

365 When using the TTC approach for risk assessment, the number of multilayer packaging materials 366 that could be used is 6 out of 20, according to FDA, and 5 out of 20, according to EFSA. 
367

368

369

370

371

372

373

374

375

376

377

378

379

380

381

382

383

384

385

386

In view of these results, gastric and intestinal digestions of the cyclic esters were performed. This study made it possible to obtain knowledge on the transformation processes of these compounds inside the human body and their bioaccessibilities.

\subsection{Digestions assays}

The aim of digestion assays was to examine if cyclic esters degraded in the stomach and intestine, thus decreasing their concentration and therefore reducing the amount of cyclic esters available to be absorbed by the body. Samples resulting from the digestion assays were analysed by UPLC-QqQ (MRM). Analytical parameters of UPLC-QqQ (MRM mode) of AA-DEG and AA-DEG-IPA-DEG standards are shown in Table 2.

The results showed that digestion led to a decrease in concentration of the cyclic polyesters. Figure 1 shows the percentage values of AA-DEG and AA-DEG-IPA-DEG oligomers after gastric (1a) and intestinal ( $1 b)$ digestions at different time points $\left(\mathrm{t}_{0}, \mathrm{t}_{1 \mathrm{~h}}, \mathrm{t}_{2 \mathrm{~h}}\right.$ and $\left.\mathrm{t}_{4 \mathrm{~h}}\right)$. These data were normalized to a control with no digestion.

The amount of both cyclic oligomers progressively decreased during digestion. For AA-DEG, the final percentages of decrease were $31.2 \%( \pm 3.9)$ and $18.2 \%( \pm 3.5)$ after gastric and intestinal digestion, respectively. Gastric digestion was more effective than intestinal digestion. An overall summary of the AA-DEG digestion can be carried out taking into account that gastric digestion occurs first and intestinal digestion happens consecutively. The digestion resulted in an overall decrease of the parent compound of $43.7 \%(\mathrm{RSD}<5 \%)$. On the other hand, for AA-DEG-IPA-DEG the final decrease after each digestion was higher, reaching $53.2 \%( \pm 2.1)$ for gastric and $91 \%( \pm$ 6.8 ) for intestinal digestion, with an overall decrease of $95.8 \%(\mathrm{RSD}<5 \%)$.

Digestion extracts were also analysed by UPLC-QTOF. Chromatograms showed the decrease of the oligomers peaks and, in addition, the emergence of new peaks with signals increasing with digestion. Figure 2 shows a chromatogram of a solution of AA-DEG (a) and AA-DEG-IPA-DEG (b) before $\left(t_{0}\right)$ and after $\left(t_{4 h}\right)$ being submitted to a gastric digestion. In both cases a new peak could be observed. The $\underline{A}$ new peaks was observed after digestions of AA-DEG were- 25.31_257.099 (retention time mass); and two peaks were observed after digestion of AA-DEG-IPA-DEG, 6.50_493.167 and 6.09 365.120AA_DEG-IPA DEG respectively. In intestinal digestion, the same analysis was carried out and the same new peaks were observed. When samples were analysed in negative mode, no differences between chromatograms before and after the digestion were observed. 


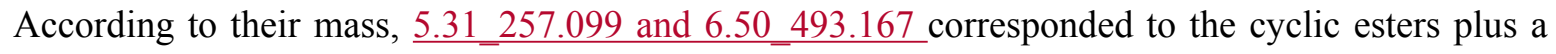
water molecule. Its formation was the consequence of the hydrolysis of the cyclic esters and the opening of the ring due to the interaction with the gastric and intestinal simulants. This hypothesis is in agreement with previous studies (Gómez Ramos, Lozano, \& Fernández-Alba, 2019; Úbeda, et al., 2017). Hydrolysed molecules always eluted before the parent molecule, as other authors have stated before (Úbeda, et al., 2017). AA-DEG high energy mass spectrum has been published in our own previous studies (Úbeda, et al., 2017). Figure 3 shows high collision energy mass spectra of AA-DEG-IPA-DEG (a) and its hydrolysed form (b) with their fragments. The spectra allowed the detection of the fragments and therefore its structure elucidation. Their common masses between cyclic and linear compound were 281.1040 and $193.0503 \mathrm{~m} / \mathrm{z}$.

The concentration of hydrolysed molecules in digestion assays was calculated using the cyclic oligomers as standards. Its evolution over time is shown in Figures 1c and 1d. Figure 1c shows concentration values of AA-DEG $+\mathrm{H} 2 \mathrm{O}$ and AA-DEG-IPA-DEG $+\mathrm{H} 2 \mathrm{O}$ during gastric digestion and Figure 1d shows concentration values of hydrolysed molecules during intestinal digestion. In gastric digestion, AA-DEG + $\mathrm{H} 2 \mathrm{O}$ concentration increased to $86.7 \mathrm{ng} \_\mathrm{g}-1$ and AA-DEG-IPA-DEG $+\mathrm{H} 2 \mathrm{O}$ to $175.4 \mathrm{ng} / \mathrm{g}_{\mathrm{g}} \mathrm{g}^{-1}$. However, after intestinal digestion, AA-DEG $+\mathrm{H} 2 \mathrm{O}$ concentration was below 6 ng g-1 $\mathrm{ng} / \mathrm{g}$ (LOD) and AA-DEG-IPA-DEG + H2O concentration was to $162.2 \mathrm{ng} \mathrm{g}^{-1} \mathrm{ng} / \mathrm{g}$.

The compound 6.09 365.120, present in the digestion of AA-DEG-IPA-DEG, was identified as DEG-IPA-DEG, coming from a breakdown of an ester linkage of the cyclic oligomer. Its structure elucidation is shown in figure $3 \mathrm{c}$.

It is important to highlight that the new compounds formed had lower toxicity according to Cramer rules (class I) which is a positive message. Transformations of cyclic esters to their opened form decreased their theoretical toxicity in most cases. Lower toxicity means a higher recommended daily intake $(1.8 \mathrm{mg} /$ person/day) and therefore, higher maximum recommended migration values, 4286 and $1800 \mathrm{ng} \mathrm{g}^{-1}$ according to FDA and EFSA, respectively. According to the migration values in Table 1, all linear oligomers were below these limits and therefore no health risk for consumers would be expected.

On the other hand, the monomers (AA, DEG and IPA) were checked. The results showed that none of the monomers were present after the oligomer digestion assays above the limits of detection

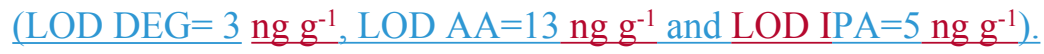


Other compounds could have been formed due to the breakdown of the different ester linkages of the oligomers during the digestion process but they were below their detection limit.

\subsection{In vitro endocrine assays}

In the present study, AA-DEG-IPA-DEG showed a statistically significant antagonistic activity on AR at high concentrations (100 and $200 \mu \mathrm{M})$ with a maximum efficacy of approximately $25 \%$ decrease compared to vehicle control. AA-DEG led to a statistically significant antagonistic effect at $200 \mu \mathrm{M}$, however the maximum efficacy was approximately $10 \%$ compared to vehicle control (Figure 4). These effects occurred at non-cytotoxic concentrations. Comparatively, AA-DEG-IPADEG thus has greater antiandrogenic potential than AA-DEG. Neither of the test compounds exhibited any major effects in the AhR reporter gene assay (Supplementary material 1) nor the ANSA-TTR assay (Supplementary material 2).

To our knowledge, this is the first time AA-DEG-IPA-DEG and AA-DEG have been tested for ability to interfere with AR, AhR, and TTR. However, the monomers DEG and IPA have been tested for AR binding both in silico and in vitro, as well as in an AR transactivation assay, but exhibited no effect (Osimitz, Welsh, Ai, \& Toole, 2015). These findings could suggest that the AA moiety of the compounds play a role in the observed antiandrogenic activities.

As a next step, we preliminarily evaluated whether the metabolites of the cyclic esters exhibited any AR antagonism. The results indicated that no active metabolites were formed at concentrations up to $12.5 \mu \mathrm{M}$ of parent compound, suggesting that the parent compounds were responsible for the activity (data not shown).

The concentrations leading to antiandrogenic activity (AA-DEG: $200 \mu \mathrm{M}$; AA-DEG-IPA-DEG: $100-200 \mu \mathrm{M})$ are greater than the migration values of the compounds under the assumption of $1 \mathrm{~kg}$ food intake per day containing the highest migration distributed in $5 \mathrm{~L}$ blood (higher migration

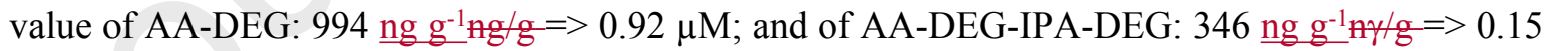
$\mu \mathrm{M})$. This suggests that the migration from a single FCM to food would not lead to a concentration that could cause inhibition of AR activity. However, humans may be exposed to oligomers from multiple FCMs simultaneously, as well as other sources, thereby increasing the exposure to these substances. In addition, multiple substances have been reported antiandrogens (Vinggaard, Niemelä, Wedebye, \& Jensen, 2008), which can exert mixture effects when exposure occur simultaneously (Metzdorff, Dalgaard, Christiansen, Axelstad, Hass, Kiersgaard, et al., 2007; Orton, Ermler, Kugathas, Rosivatz, Scholze, \& Kortenkamp, 2014). Therefore, a better understanding of human exposure sources as well as human levels are needed in future studies. 


\section{Conclusions}

464 The migration values of the cyclic polyesters that are formed during PU manufacturing (AA-DEG 465 and AA-DEG-IPA-DEG), was highly variable for the different multilayer materials studied. The PU manufacturing process together with the physico-chemical materials properties and the migration conditions could be the explanation for these differences. Besides, results showed that AA-DEG migrated more than AA-DEG-IPA-DEG, probably due to its smaller structure and the absence of the aromatic ring.

470

471

472

The digestion studies showed that the cyclic esters were degraded significantly after gastric and intestinal digestion, which was very positive because their bioaccessibility to the human body became lower. In addition, the new compounds formed had lower toxicity according to Cramer rules, what was also positive from a food safety and human health perspective.

The digestion processes affected the two cyclic esters differently. In the case of AA-DEG, gastric digestion influenced the most with a decrease of $31 \%$, whereas in the case of AA-DEG-IPA-DEG, the influence of intestinal digestion was greater (decrease of 91\%). Global digestion (gastric plus intestinal digestion) was more dominant for AA-DEG-IPA-DEG than for AA-DEG. This means that the bioaccessibility of AA-DEG-IPA-DEG is expected to be lower than of AA-DEG.

Regarding to the endocrine activity, slight effects were observed on AR activity at higher test concentrations suggesting that the compounds can act as AR antagonists. When comparing the compounds, AA-DEG had lower antagonistic activity than AA-DEG-IPA-DEG. This can be hypothesized to be due to the fact that this last compound has a phthalate as part of its chemical structure. Monomers have so far shown no toxicity but their oligomers has slightly AR activity. No effect on TTR binding or AhR activity was found. It may be hypothesized that this lack of effects in vitro might be due to the large size of these molecules that may hinder accessibility to the target.

It would be interesting to perform a broader in vitro screening to expand the toxicological knowledge on these compounds.

\section{Acknowledgments}

The authors would like to acknowledge Projects AGL2015-67362-P from MINECO (Spain) and FEDER funds and Project RYC-2012-11856 (Ramón y Cajal Research Program). The authors thank 
the Aragon Government and Fondo Social Europeo for the financial help given to GUIA group T53_17R. Ubeda is supported by the grant/contract number BES-2016-077159.

Potential conflicts of interest do not exist

\section{References}

Aznar, M., Gómez-Estaca, J., Vélez, D., Devesa, V., \& Nerín, C. (2013). Migrants determination and bioaccessibility study of ethyl lauroyl arginate (LAE) from a LAE based antimicrobial food packaging material. Food and Chemical Toxicology, 56, 363-370.

Aznar, M., Ubeda, S., Dreolin, N., \& Nerín, C. (2019). Determination of non-volatile components of a biodegradable food packaging material based on polyester and polylactic acid (PLA) and its migration to food simulants. Journal of Chromatography A, 1583, 1-8.

Aznar, M., Vera, P., Canellas, E., Nerín, C., Mercea, P., \& Störmer, A. (2011). Composition of the adhesives used in food packaging multilayer materials and migration studies from packaging to food. Journal of Materials Chemistry, 21(12), 4358-4370.

Campanella, G., Ghaani, M., Quetti, G., \& Farris, S. (2015). On the origin of primary aromatic amines in food packaging materials. Trends in Food Science \& Technology, 46(1), 137-143.

Duntas, L. H., \& Stathatos, N. (2015). Toxic chemicals and thyroid function: hard facts and lateral thinking. Reviews in Endocrine and Metabolic Disorders, 16(4), 311-318.

EC. (2004). Regulation (EU) No. 1935/2004 of European Parliament and of the Council of 27 October 2004 on materials and articles intended to come tinto contact with food and repealing directies 80/590/ECC. Official Journal of the European Union L338:4.

EC. (2011). Commission regulation (EU) No 10/2011 of 14 January 2011 on plastic materials and articles intended to come into contact with food. Official Journal of the European Union(L 12:1 89).

Eceiza, A., Martin, M. D., de la Caba, K., Kortaberria, G., Gabilondo, N., Corcuera, M. A., \& Mondragon, I. (2008). Thermoplastic polyurethane elastomers based on polycarbonate diols with different soft segment molecular weight and chemical structure: Mechanical and thermal properties. Polymer Engineering \& Science, 48(2), 297-306.

EFSA. (2008). Note for guidance: For the preparation of an application for the safety assessment of a substance to be used in plastic food contact materials. EFSA Journal.

EFSA. (2009). Scientific Opinion on the safety evaluation of the substance, cyclic oligomers of (butylene terephthalate), CAS No. 263244-54-8, for use in food contact materials. EFSA Journal.

EFSA. (2012). Scientific Opinion on Exploring options for providing advice about possible human health risks based on the concept of Threshold of Toxicological Concern (TTC). EFSA Journal, 10(7), 2750.

Engels, H.-W., Pirkl, H.-G., Albers, R., Albach, R. W., Krause, J., Hoffmann, A., Casselmann, H., \& Dormish, J. (2013). Polyurethanes: Versatile Materials and Sustainable Problem Solvers for Today's Challenges. Angewandte Chemie International Edition, 52(36), 9422-9441.

Esser, C., \& Rannug, A. (2015). The Aryl Hydrocarbon Receptor in Barrier Organ Physiology, Immunology, and Toxicology. Pharmacological Reviews, 67(2), 259-279.

Félix, J. S., Isella, F., Bosetti, O., \& Nerín, C. (2012). Analytical tools for identification of nonintentionally added substances (NIAS) coming from polyurethane adhesives in multilayer 
packaging materials and their migration into food simulants. Analytical and Bioanalytical Chemistry, 403(10), 2869-2882.

G. M. Cramer, G. M., Ford, R. A., \& Hall, R. L. (1978). Estimation of Toxic Hazard-A Decision Tree Aproach. Food and Cosmetics Toxicology, 16:255-276.

Gelbke, H.-P., Banton, M., Block, C., Dawkins, G., Leibold, E., Pemberton, M., Sakoda, A., \& Yasukawa, A. (2018). Oligomers of styrene are not endocrine disruptors. Critical Reviews in Toxicology, 48(6), 471-499.

Gómez Ramos, M. J., Lozano, A., \& Fernández-Alba, A. R. (2019). High-resolution mass spectrometry with data independent acquisition for the comprehensive non-targeted analysis of migrating chemicals coming from multilayer plastic packaging materials used for fruit purée and juice. Talanta, 191, 180-192.

Grob, K., Camus, P., Gontard, N., Hoellinger, H., Joly, C., Macherey, A. C., Masset, D., Nesslany, F., Régnier, J. F., Riquet, A. M., Saillard, P., \& Ribera, D. (2010). Need for a better safety evaluation of food contact materials produced from resins. Food Control, 21(5), 763-769.

Guidelines for the Testing of Chemicals, O. (2016). Section 4: Health Effects: Test No. 458: Stably Transfected Human Androgen Receptor Transcriptional Activation Assay for Detection of Androgenic Agonist and Antagonist Activity of Chemicals

Heath, D. E., \& Cooper, S. L. (2013). A - Polyurethanes. In B. D. Ratner, A. S. Hoffman, F. J. Schoen \& J. E. Lemons (Eds.), Biomaterials Science (Third Edition), (pp. 79-82): Academic Press.

Hoppe, M., de Voogt, P., \& Franz, R. (2016). Identification and quantification of oligomers as potential migrants in plastics food contact materials with a focus in polycondensates - A review. Trends in Food Science \& Technology, 50, 118-130.

Metzdorff, S. B., Dalgaard, M., Christiansen, S., Axelstad, M., Hass, U., Kiersgaard, M. K., Scholze, M., Kortenkamp, A., \& Vinggaard, A. M. (2007). Dysgenesis and Histological Changes of Genitals and Perturbations of Gene Expression in Male Rats after In Utero Exposure to Antiandrogen Mixtures. Toxicological Sciences, 98(1), 87-98.

Nelson, C. P., Patton, G. W., Arvidson, K., Lee, H., \& Twaroski, M. L. (2011). Assessing the toxicity of polymeric food-contact substances. Food and Chemical Toxicology, 49(9), 1877-1897.

Nerin, C., Alfaro, P., Aznar, M., \& Domeño, C. (2013). The challenge of identifying nonintentionally added substances from food packaging materials: A review. Analytica Chimica Acta, 775, 14-24.

Orton, F., Ermler, S., Kugathas, S., Rosivatz, E., Scholze, M., \& Kortenkamp, A. (2014). Mixture effects at very low doses with combinations of anti-androgenic pesticides, antioxidants, industrial pollutant and chemicals used in personal care products. Toxicology and Applied Pharmacology, 278(3), 201-208.

Osimitz, T. G., Welsh, W. J., Ai, N., \& Toole, C. (2015). Polyester monomers lack ability to bind and activate both androgenic and estrogenic receptors as determined by In Vitro and In Silico methods. Food and Chemical Toxicology, 75, 128-138.

Pietropaolo, E., Albenga, R., Gosetti, F., Toson, V., Koster, S., Marin-Kuan, M., Veyrand, J., Patin, A., Schilter, B., Pistone, A., \& Tei, L. (2018). Synthesis, identification and quantification of oligomers from polyester coatings for metal packaging. Journal of Chromatography A, $1578,15-27$.

PlasticsEurope. (2014). Risk Assessment of non-listed substances (NLS) and non-intentionally added substances (NIAS) under Article 19 of Commission Regulation (EU) No 10/2011 of 14 January 2011 on plastic materials and articles intended to come into contact with food.

Rosenmai, A. K., Taxvig, C., Wedebye, E. B., Dybdahl, M., Vinggaard, A. M., Pedersen, M., \& Alice van Vugt-Lussenburg, B. M. (2014). Are Structural Analogues to Bisphenol A Safe Alternatives? Toxicological Sciences, 139(1), 35-47. 
611

612

613

614

615

616

617

618
Schwartz, C. L., Christiansen, S., Vinggaard, A. M., Axelstad, M., Hass, U., \& Svingen, T. (2019). Anogenital distance as a toxicological or clinical marker for fetal androgen action and risk for reproductive disorders. Archives of Toxicology, 93(2), 253-272.

Shrikhande, A. (2012). Migration studies and chemical characterization of short chain cyclic polyester oligomers from food packaging laminate adhesives. Unpublished Thesis, The State University of New Jersey.

Swiss-Confederation. (2013). Ordinanza del DFI sui materiali e gli oggetti destinati a entrare in contatto con le derrate alimentari (RS 817.023.21).

Tehrany, E. A., \& Desobry, S. (2004). Partition coefficients in food/packaging systems: a review. Food Additives \& Contaminants, 21(12), 1186-1202.

Ubeda, S., Aznar, M., Alfaro, P., \& Nerín, C. (2019). Migration of oligomers from a food contact biopolymer based on polylactic acid (PLA) and polyester. Analytical and Bioanalytical Chemistry.

Ubeda, S., Aznar, M., \& Nerín, C. (2018). Determination of oligomers in virgin and recycled polyethylene terephthalate (PET) samples by UPLC-MS-QTOF. Analytical and Bioanalytical Chemistry, 410(9), 2377-2384.

Úbeda, S., Aznar, M., Vera, P., Nerín, C., Henríquez, L., Taborda, L., \& Restrepo, C. (2017). Overall and specific migration from multilayer high barrier food contact materials - kinetic study of cyclic polyester oligomers migration. Food additives \& contaminants. Part A, Chemistry, analysis, control, exposure \& risk assessment, 34(10), 1784-1794.

Vinggaard, A. M., Niemelä, J., Wedebye, E. B., \& Jensen, G. E. (2008). Screening of 397 Chemicals and Development of a Quantitative Structure-Activity Relationship Model for Androgen Receptor Antagonism. Chemical Research in Toxicology, 21(4), 813-823.

Wrona, M., \& Nerín, C. (2019). CHAPTER 7. Risk Assessment of Plastic Packaging for Food Applications: Mass Spectrometry Techniques. In, (pp. 163-191).

Zhang, N. (2014). Analytical in vitro and invivo metabolic studies of short chain cyclic polyester oligomers (lactones) from polyurethane laminating adhesives. The State University of New Jersey.

Zhang, N., Kenion, G., Bankmann, D., Mezouari, S., \& Hartman, T. G. (2018). Migration studies and chemical characterization of low molecular weight cyclic polyester oligomers from food packaging lamination adhesives. Packaging Technology and Science, 31(4), 197-211. 
621 Fig 1. Decrease percentage evolution of AA-DEG and AA-DEG-IPA-DEG oligomers for gastric (a) 622 and intestinal (b) digestion over time $\left(\mathrm{t}_{0}, \mathrm{t}_{1 \mathrm{~h}}, \mathrm{t}_{2 \mathrm{~h}}\right.$ and $\left.\mathrm{t}_{4 \mathrm{~h}}\right)$. Evolution of concentration of AA-DEG + $623 \mathrm{H}_{2} \mathrm{O}$ and AA-DEG-IPA-DEG $+\mathrm{H}_{2} \mathrm{O}$ oligomers for gastric (c) and intestinal (d) digestion over time $624\left(\mathrm{t}_{0}, \mathrm{t}_{1 \mathrm{~h}}, \mathrm{t}_{2 \mathrm{~h}}\right.$ and $\left.\mathrm{t}_{4 \mathrm{~h}}\right)$.

625 Fig 2. Chromatograms of AA-DEG (a) and AA-DEG-IPA-DEG (b) in gastric digestion assays at 626 time 0 and after 4 hours by UPLC-_MS-QTOF.

627 Fig 3. High collision energy spectra for AA-DEG-IPA-DEG (a), its hydrolysed form (b)_and a 628 fragmentation product, DEG-IPA-DEG (c)

629 Fig 4. Agonism, antagonism and cytotoxicity data from the androgen receptor reporter gene assay 630 of AA-DEG-IPA-DEG (up) and AA-DEG (down) oligomer. Data presented normalized to the 631 vehicle control as pooled means from 7 independent experiments (mean $\pm S D, n=7$ ). *indicates 632 significant differences $(\mathrm{p}<0.05)$. 